\title{
Readiness of Medical Teams Caring for COVID-19 in the Intensive Care Units: A National Web-Based Survey in Indonesia
}

\author{
Mochamat Helmi $^{1 *}$ (D), Djayanti Sari ${ }^{2}$ iD, Andreasta Meliala $^{3}$ D, Laksono Trisnantoro $^{3}$ (D) \\ ${ }^{1}$ Department of Anesthesiology, Faculty of Medicine, Universitas Tarumanagara, Jakarta, Indonesia; ${ }^{2}$ Department of \\ Anesthesiology and Intensive Care, Faculty of Medicine, Public Health and Nursing, Universitas Gadjah Mada, Jogjakarta, \\ Indonesia; ${ }^{3}$ Department of Health Policy and Management, Faculty of Medicine, Public Health and Nursing, Universitas Gadjah \\ Mada, Jogjakarta, Indonesia
}

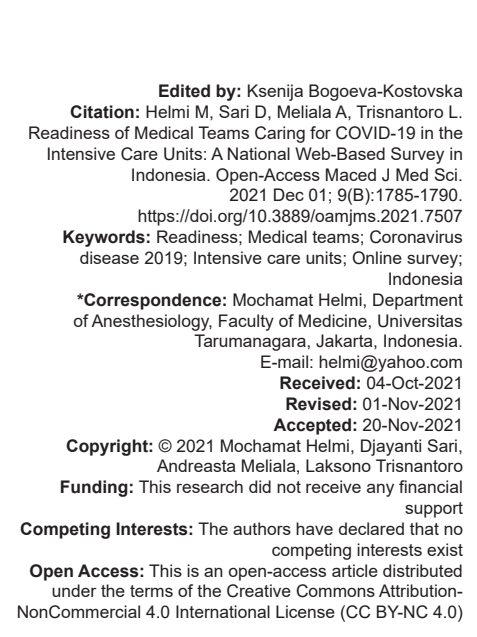

\section{Introduction}

The pandemic of coronavirus disease 2019 (COVID-19) has caused health care institutions to rethink how they allocate scarce medical resources to the highest priority patients [1]. Many confirmed cases, especially those with comorbidities, are more prone to develop critical diseases including respiratory and cardiac failure or shock, which may necessitate invasive breathing assistance or extracorporeal hemodynamic support [2]. According to Li et al. [3], there is an exceedingly high rate of intensive care unit (ICU) death during a 28-day period $(62 \%)$; this rate is higher than the rate associated with severe acute respiratory distress syndrome [4]. According to the $\mathrm{WHO}$ recommendations, the ratio of ICU beds to population should be 5 beds $/ 1000$ people [5]. Furthermore, Indonesia ICU bed ratio is 3 beds $/ 100,000$ people, lower than Malaysia [6]. This is still far from the ICU ratio in Indonesia. Thus, the ICU in Indonesia must be prepared to deal with around $10 \%$ of all COVID-19 patients [6]. The limited number of ICU is poorly distributed to meet the needs of ICU services throughout Indonesia.

Indonesia as of May 1, 2020, had 2321 anesthesiologists to serve a $272,000,000$ people [6] Anesthesiologists are responsible for a population of $1: 855,345$ persons, whereas physicians are responsible for 117,190 people [6]. Previous research indicated that medical professionals were scarce during the COVID19 pandemic. For example, the previous study reported a shortage of medical personnel in the emergency department and ICU, requiring surgeons or obstetricians to fill in [7]. The COVID-19 pandemic has caused many limitations in personal protective equipment (PPE), especially mask N95, machine ventilator, and other devices that support critical and specialized care (continuous renal replacement therapy, extracorporeal membrane oxygenation, and hemodynamic monitors), and treatment devices (flow oxygen sensors and closed suction) [8], [9].

The COVID-19 pandemic as a biological disaster caused a surge in capacity in many countries 
around the world. In response to the pandemic, the majority of referral institutions rapidly ramped up their preparedness and created novel protocols to limit disease transmission and train their staff to care for COVID-19 patients [10], [11]. A recent study suggests that the Indonesian system lacks appropriate surge capacity and would benefit from a well-organized, nationally led, and integrated approach [12], [13]. The previous studies emphasized that hospital surge capacity should space, staff, medical equipment and drugs, and systems [14]. There were no specified standards for measuring hospital surge capacity preparedness. In addition, there was a scarcity of information about the magnitude of the actual adjustments that ICUs have made and their efforts to improving pandemic readiness [15]. It is critical to assess the readiness of medical teams caring for patients with COVID-19 in ICUs to identify gaps and inform changes as we prepare for current and future COVID-19 pandemic waves. However, the preparedness and capacity of medical team to respond to COVID-19 in Indonesia is remained unknown. This survey aims to describe the current readiness efforts among ICU medical team at the COVID-19 referral hospitals in Indonesia; space, stuff readiness, staff, and systems readiness.

\section{Materials and Methods}

\section{Survey design and setting}

We conducted a cross-sectional study. Crosssectional studies are frequently faster and cheaper than prospective cohort studies, and can be used for public health planning, monitoring, and assessment [16]. This study included 15 referral hospitals for COVID-19 in Indonesia including vertical and district hospitals from June to October 2020. A web-based survey was chosen to prevent the transmission of COVID-19.

\section{Samples}

The sample in this study was medical team working in ICU that provides direct care to patients with COVID-19. The inclusion criteria were general practitioners, intern doctors, anesthesia residents, anesthesiologists, and intensive care consultants who are actively involved in delivering COVID-19 services and willing to respond. A power analysis was used to determine the sample size, with a power of 0.80 , an alpha of 0.05 , and a moderate effect size. There were minimum 120 people who needed to be included in the study. A convenience sample was used to select participants.

\section{Survey development}

The questionnaire was developed by researchers, physicians, and academics with experience in intensive critical care, disaster preparedness, and survey development. The survey was pretested for length and readability at three different ICUs that were not included in the study to improve the face and content. The medical teams survey included 53 questions in multiple parts addressing four dimensions [14]: (1) Demographics characteristics; (2) space readiness (10 items); (3) stuff readiness (8 items); (4) staff readiness (16 items); and (5) systems readiness (19 items). Spaces refers to an ICU readiness to provide care for patients with COVID-19. Space encompasses zoning, standard ICU including availability and appropriateness, insulation and non-insulation. Stuff refers to the logistical readiness of the COVID-19 ICU to provide services; its included personal protection equipment and medical assistance. Medical team preparedness refers to ability in providing care to COVID-19 patients in ICU. Staff included the number and distribution of expert physicians and their qualifications, medical team screening, and their knowledge and competency. System refers to the service system readiness to provide ICU COVID-19 services. System included health insurance (workload and quarantine protection), legal insurance (disaster management policy system), an incentive scheme, and a command system which are all included in the system. The instrument used Likert scale with 1 (strongly disagree) to 5 (strongly agree). High scores indicate a high level of preparation. The validity test was conducted 318 medical team, which reported the factor loadings of $0.60-0.71$ for each item. All composite reliability was declared reliable at $0.59-0.73$.

\section{Procedures and ethical considerations}

The ethics committee of the affiliated institution (Faculty of Medicine, Universitas Gajah Mada) approved this study (reference number: KE/FK/0742/ $E C / 2020$ ), and all participants provided informed consent through a checklist box on the online survey. To ensure informed consent, a consistent framework was utilized to tell respondents about the study's purpose and privacy procedures. Respondents may complete the survey using a computer or a smartphone, which may launch a website or verify a fast response code.

\section{Statistical analysis}

Percentages were used to describe categorical data, whereas means and standard deviations were used to represent continuous variables (SD). We conducted bivariate analysis using the Student's t-test for continuous data and the Chi-square test for categorical data. A linear regression model was applied to determine the factors related with readiness. $p<0.05$ 
was judged significant statistically. SPSS 22.0 was used to analyze the data collected.

\section{Results}

A total of 459 participants (83.6\%) agreed to join in this study. The participants average age was 40.43 years old $(S D=5.78)$. About $62.53 \%$ were male, $51.20 \%$ had bachelor degree, and $55.77 \%$ lived outside Java Island. The mean age of working experience was $9.53(S D=2.08)$ and mean of perception of risk of contracting COVID-19 was 3.46 $(\mathrm{SD}=0.75)$ (Table 1).

Table 1: Demographic characteristics $(n=459)$

\begin{tabular}{lll}
\hline Variables & $\mathrm{n}$ & $\%$ \\
\hline Age, Mean \pm SD & $40.43 \pm 5.78$ & \\
Gender & & \\
$\quad$ Female & 172 & 37.47 \\
$\quad$ Male & 287 & 62.53 \\
Education level & & \\
$\quad$ Bachelor degree & 235 & 51.20 \\
$\quad$ Specialist grade 1 & 164 & 35.73 \\
$\quad$ Specialist grade 2 & 60 & 13.07 \\
$\quad$ Working experience, year (Mean \pm SD) & 9.53 & 2.08 \\
Have been trained for universal precaution & 306 & 66.67 \\
$\quad$ Yes & 153 & 33.33 \\
$\quad$ No & $3.46 \pm 0.75$ & \\
Perception of contracting COVID-19 risk (Mean \pm SD) & & \\
Origin & 203 & 44.23 \\
$\quad$ Java Island & 256 & 55.77 \\
$\quad$ Outside Java Island & & \\
\hline
\end{tabular}

The mean and SD derived from the medical team readiness are shown in Table 2 . The mean of total score of medical team readiness was $2.76(S D=0.320)$. The higher mean score of medical team readiness domain was stuff, followed by staff readiness, space readiness, and the systems-related readiness.

Table 2: Distribution of means and standard deviations of medical team readiness caring for COVID-19 in the ICUs ( $n=459$ )

\begin{tabular}{lll}
\hline Variables & Mean \pm SD & Range \\
\hline Medical team readiness & $2.76 \pm 0.32$ & $1-5$ \\
Space-related readiness & $2.35 \pm 0.72$ & $1-5$ \\
Stuff-related readiness & $2.81 \pm 0.11$ & $1-5$ \\
Staff-related readiness & $2.51 \pm 0.46$ & $1-5$ \\
System-related readiness & $2.33 \pm 0.32$ & $1-5$ \\
\hline
\end{tabular}

Age, working experience, perception of risk of contracting COVID-19, and residence were significantly associated with space-related readiness ( $p<0.05$ ). Age, gender, working experience, perception of risk of contracting COVID-19, and residence were significantly associated with stuff-related readiness $(p<0.05)$. Then, age, gender, education background, working experience, training, perception of risk of contracting COVID-19, and residence were significantly associated with staff-related readiness $(p<0.05)$. Finally, working experience, training, perception of risk of contracting COVID-19, and residence were significantly associated with system-related readiness $(p<0.05)$ (Table 3$)$.

Education, working experience, training, perception of contracting COVID-19 risk, and origin had a substantial effect on the readiness, with $R^{2}$ values of 0.378, $\mathrm{p}<0.05$ (Table 4).

\section{Discussion}

Findings of this study indicated that the readiness of the medical team was still lacking in several dimensions. Similarly, previous cross-sectional study to evaluate hospitals disaster readiness in South Yemen indicated that hospitals had not yet attained an intolerable level of preparation [17]. Previous crosssectional study in multiple Iranian hospitals using found similar results [18]. Medical team readiness analysis is necessary to support hospital administration in providing the following: (1) Continuity of vital services, (2) well-coordinated implementation of priority actions, (3) accurate internal and external communication, and (4) appropriate adaptation. timely reaction to growing demand, (5) efficient use of restricted resources, and (6) a safe working environment for health care professionals [19]. The WHO has released a "Hospital Readiness Checklist for COVID-19" for use in Europe as part of a continuous hospital emergency preparedness effort [20]. Continuity of essential health services and patient care, surveillance: Early warning and monitoring, communications, logistics, and supply chain management including pharmaceuticals, laboratory services, and essential support services are all

Table 3: Correlation of medical team readiness with the participants' characteristics $(n=459)$

\begin{tabular}{|c|c|c|c|c|c|c|c|c|}
\hline \multirow[t]{2}{*}{ Variables } & \multicolumn{2}{|l|}{ Space } & \multicolumn{2}{|l|}{ Stuff } & \multicolumn{2}{|l|}{ Staff } & \multicolumn{2}{|l|}{ Systems } \\
\hline & Mean \pm SD & $\mathrm{p}$-value & Mean \pm SD & p-value & Mean \pm SD & $\mathrm{p}$-value & p-value & p-value \\
\hline Age, year (Mean \pm SD) & & $0.034^{\mathrm{a}}$ & & $0.029^{a}$ & & $0.003^{\mathrm{a}}$ & & $0.128^{\mathrm{a}}$ \\
\hline \multicolumn{9}{|l|}{ Gender } \\
\hline Male & $2.97 \pm 0.46$ & 0.986 & $2.36 \pm 0.13$ & 0.021 & $2.66 \pm 0.16$ & 0.039 & $2.73 \pm 1.16$ & 0.413 \\
\hline Female & $2.99 \pm 0.11$ & & $3.72 \pm 1.51$ & & $3.55 \pm 1.08$ & & $2.25 \pm 1.09$ & \\
\hline \multicolumn{9}{|l|}{ Education level } \\
\hline Bachelor degree & $2.39 \pm 0.82$ & 0.083 & $2.46 \pm 0.74$ & 0.120 & $2.30 \pm 0.65$ & 0.001 & $2.04 \pm 0.38$ & 0.078 \\
\hline Specialist grade 1 & $2.00 \pm 0.39$ & & $2.00 \pm 0.36$ & & $3.22 \pm 1.07$ & & $2.95 \pm 0.31$ & \\
\hline Specialist grade 2 & $2.42 \pm 0.31$ & & $2.62 \pm 0.20$ & & $3.98 \pm 1.81$ & & $2.13 \pm 0.66$ & \\
\hline Working experience, year (Mean \pm SD) & & $0.032^{\mathrm{a}}$ & & $0.001^{\mathrm{a}}$ & & $0.001^{\mathrm{a}}$ & & $0.021^{\mathrm{a}}$ \\
\hline \multicolumn{9}{|l|}{ Have been trained for universal precaution } \\
\hline \multirow{2}{*}{\multicolumn{9}{|c|}{$\begin{array}{l}\text { Yes } \\
\text { No }\end{array}$}} \\
\hline & & & & & & & & \\
\hline Perception of contracting COVID-19 risk, (Mean \pm SD) & & $0.003^{\mathrm{a}}$ & & $0.001^{\mathrm{a}}$ & & $0.001^{\mathrm{a}}$ & & $0.015^{\mathrm{a}}$ \\
\hline \multicolumn{9}{|l|}{ Origin } \\
\hline Java Island & $3.28 \pm 0.59$ & 0.021 & $3.37 \pm 1.83$ & 0.026 & $3.93 \pm 1.56$ & 0.043 & $3.82 \pm 1.95$ & $0.001^{\mathrm{a}}$ \\
\hline Outside Java Island & $2.43 \pm 1.62$ & & $2.16 \pm 0.50$ & & $2.03 \pm 0.35$ & & $2.04 \pm 0.41$ & \\
\hline
\end{tabular}


recommendation. In an outbreak, hospitals may struggle to satisfy demand and capacity may be exceeded [21]. Even hospitals adequately equipped for disasters would struggle to deal with the pandemic. The hospital disaster preparedness strategy must include provisions for medical team readiness in the event of a disaster. Therefore, the hospital disaster management plan is critical, as it will ensure that the hospital is prepared in the event of a crisis, resulting in less confusion and a more efficient, effective, and reasonable response [22].

Table 4: Factors associated with medical team readiness caring for coronavirus disease 2019 in the ICUs $(n=459)$

\begin{tabular}{lll}
\hline Variable & Readiness & \\
\cline { 2 - 3 } & $\mathrm{B}(\mathrm{SE})$ & $\mathrm{p}$-value \\
\hline Age & $0.601(0.221)$ & 0.457 \\
Gender (Male vs. female) & $0.568(0.867)$ & 0.534 \\
Education (Bachelor vs. specialist) & $2.423(0.474)$ & 0.023 \\
Working experience & $2.578(0.143)$ & 0.014 \\
Training (Yes vs. no) & $3.216(0.244)$ & $<0.001$ \\
Perception of contracting COVID-19 risk & $2.367(0.087)$ & 0.011 \\
Residence (Java vs. outside Java Island) & $1.953(0.654)$ & 0.022 \\
$\mathrm{R}^{2}$ & 0.378 & \\
\hline Bold: Significant ( $\mathrm{p}<0.05)$. ICU: Intensive care unit. & &
\end{tabular}

The findings indicated that stuff readiness was the highest priority need to be prepared. In the current pandemic situation in Indonesia, the first constraint that must be addressed is the scarcity of isolation rooms that fulfill standards in terms of size, equipment, and the presence of negative pressure facilities and anterooms. It is known that the majority of hospitals do not have enough isolation rooms - to deal with the increasing patient numbers during the COVID-19 pandemic peak [9]. It's important to improve capacity of medical team in ICU to provide health and medical services in during the surge capacity of COVID-19 pandemic. The COVID-19 pandemic has raised healthcare policymaker awareness of the importance of establishing an isolation area for patients with airborne illnesses or immunocompromised. Separate isolation rooms should be provided for the two types of isolation rooms due to differing air pressure needs. Positive pressure isolation rooms should be utilized for immunocompromised patients and negative pressure isolation rooms for infectious diseases [23].

The availability of stuff or medical equipment was the second important issued to prepare during the COVID-19 pandemic in Indonesia, specifically PPE, ventilator machines, and other supporting tools for critical and special care. However, the limitations medical equipment are a global issue during COVID19 pandemic [24]. The use of PPE, particularly hazmat, eye protection, or face shields, increased the likelihood of trash being disposed of in landfills, whereas reuse requires a thorough decontamination process. There is a scarcity of PPE available, either due to an increase in the number of patients or due to inadequate manufacture of PPE, and the situation is designated as a crisis by the Health Service Center leadership, alternate uses of PPE must be considered. This technique may be used to meet the requirement for PPE when treating COVID19 patients [25].
The medical team readiness was influenced by the health management managers ability to identify what is required to deal with the COVID-19 pandemic. Staff availability complements the limited resources that must be anticipated during a COVID-19 patient surge. The availability of employees in dealing with the COVID19 pandemic must be examined, particularly in terms of competence and credentials, age, comorbidities, infection status, and the staff ability or willingness to deliver services to COVID-19 patients [26]. In addition, tracking the predicted peak of the pandemic phase is part of the identification process, allowing for specific strategies to be implemented overtime [27]. Several recommendations, such as those obtained from international/national health organizations or from professional associations, can simply provide the current list of standards of care [28], [29]. However, it should be noted that not all hospitals are able to provide a system that is supported by standardized $3 S$ (stuff, staff, and systems) in accordance with the requirements, particularly in the pandemic era, when all health services throughout the world must be available at the same time [18], [23], [24]. Therefore, hospital administrators must be able to develop a new system which provide good, safe, and quality services, while also coordinating, providing information, and coordinating with all necessary parties.

Education, working experience, and training were associated with medical team readiness. Inadequate knowledge is a risk factor for disease transmission, as it can lead to low levels of care. Moreover, study conducted a cross-sectional study in Malaysia aimed to determine the factors that contribute to disaster preparedness and hospital resilience found that human resources and training, the ability to change quickly were identified as the most crucial factors [23]. Meanwhile, no official courses or training programs of COVID-19 are available. Our study provides considerable insights into the necessity of immediate and determined efforts focused on training programs and providing an adequate supply of PPE to alleviate these challenges during the COVID-19 pandemic. More training and education are needed on the triage and isolation of suspected cases [30]. Residence or origin of participants was associated with medical team readiness. It might due to difference in governance and hospital infrastructure facilities in each region, especially in the area outside the Java Island [6]. Moreover, many medical teams have higher perception of contracting COVID-19 risk. This might due to they were unaware of isolation room specifications and processes for potential COVID-19 patients, which could increase the risk of infection within hospitals [30]. Training and safety precautions, focused on the direct decontamination of contact points among health care workers, are needed to prevent the spread of infection [31], [32]. Furthermore, we did not find any correlation between age and gender with medical team readiness. The medical team has a significant role and responsibility 
to COVID-19 prevention and management. This significant responsibility called for all medical team regardless their age or gender.

\section{Study limitation}

The study also has a number of limitations. First, the small sample size of our study may have a substantial impact on the generalizability of the findings. Because of its cross-sectional nature, it is possible to draw associations rather than causal conclusions from this study. Future studies may conduct longitudinal design to provide more comprehensive and dynamic change of medical team preparedness during the pandemic COVID-19. Due to the fact that the research data were collected during the first wave of the COVID-19 outbreak in Indonesia, sufficient time should have passed for preparedness to emerge. Future research in Indonesia should focus on comparing readiness between the initial and secondary waves of the COVID-19 pandemic utilizing a mixed method approach.

\section{Conclusions}

This study found that the medical team preparedness was still lacking in several dimensions including space preparedness, stuff or medical equipment preparedness, staff preparedness, and system preparedness. This study provides an initial view of current preparedness efforts among a group of leading ICUs in Indonesia during the first wave of COVID-19 pandemic. This COVID-19 pandemic poses a significant threat to medical team readiness throughout the world, and by understanding the lessons learnt from the first wave, effective solutions for subsequent waves can be implemented. Interventions must be developed and implemented quickly to medical team preparedness in providing care for patients with COVID-19 at the ICU. Governments and policymakers should better prepare health-care systems and medical team for future pandemic.

\section{References}

1. Emanuel EJ, Persad G, Upshur R, Thome B, Parker M, Glickman $\mathrm{A}$, et al. Fair allocation of scarce medical resources in the time of Covid-19. N Engl J Med. 2020;382(21):2049-55. http://doi.org/10.1056/NEJMsb2005114 PMid:32202722

2. Kache S, Chisti MJ, Gumbo F, Mupere E, Zhi X, Nallasamy K, et al. COVID-19 PICU guidelines: For high- and limited-resource settings. Pediatr Res. 2020;88(5):705-16. http://doi.org/10.1038/ s41390-020-1053-9

\section{PMid:32634818}

3. Li B, Yang J, Zhao F, Zhi L, Wang X, Liu L, et al. Prevalence and impact of cardiovascular metabolic diseases on COVID19 in China. Clin Res Cardiol. 2020;109(5):531-8. http://doi. org/10.1007/s00392-020-01626-9

PMid:32161990

4. Bellani G, Laffey JG, Pham T, Fan E, LUNG SAFE Investigators and the ESICM Trials Group. The LUNG SAFE study: A presentation of the prevalence of ARDS according to the Berlin definition! Crit Care. 2016;20:268. http://doi.org/10.1186/ s13054-016-1443-x

PMid:27608629

5. World Health Organization. Task Shifting: Global Recommendation: Geneva: World Health Organization; 2008.

6. Ministry of Health. Designation of Reference Hospitals for the Management of Specific Emerging Infectious Diseases. Jakarta: Ministry of Health; 2020.

7. Giulio M, Maggioni D, Montroni I, Ugolini G, Capelli P, Ceppi L, et al. Being a doctor will never be the same after the COVID-19 pandemic. Am J Med. 2020;133(6):652. http://doi.org/10.1016/j. amjmed.2020.03.003

PMid:32240630

8. White DB, Lo B. A framework for rationing ventilators and critical care beds during the COVID-19 pandemic. JAMA. 2020;323(18):1773-4. http://doi.org/10.1001/jama.2020.5046

PMid:32219367

9. Wujtewicz MA, Dylczyk-Sommer A, Aszkiełowicz A Zdanowski S, Piwowarczyk S, Owczuk R. COVID-19-what should anaethesiologists and intensivists know about it? Anaesthesiol Intensive Ther. 2020;52(1):34-41. http://doi. org/10.5114/ait.2020.93756

\section{PMid:32191830}

10. Guris RJ, Doshi A, Boyer DL, Good G, Gurnaney HG, Rosenblatt $\mathrm{S}$, et al. Just-in-time simulation to guide workflow design for coronavirus disease 2019 difficult airway management. Pediatr Crit care Med. 2020;21(8):e485-90. http:// doi.org/10.1097/PCC.0000000000002435

PMid:32459793

11. O'Meara AM, Sequeira J, Ferguson NM. Advances and future directions of diagnosis and management of pediatric abusive head trauma: A review of the literature. Front Neurol. 2020;11:118. http://doi.org/10.3389/fneur.2020.00118 PMid:32153494

12. Bohn D, Kanter RK, Burns J, Barfield WD, Kissoon N, Task Force for Pediatric Emergency Mass Critical Care. Supplies and equipment for pediatric emergency mass critical care. Pediatr Crit care Med. 2011;12(6 Suppl):S120-7. http://doi.org/10.1097/ PCC.0b013e318234a6b9

PMid:22067920

13. Barfield WD, Krug SE, Kanter RK, Gausche-Hill M, Brantley MD, Chung S, et al. Neonatal and pediatric regionalized systems in pediatric emergency mass critical care. Pediatr Crit Care Med. 2011;12(6 Suppl):S128-34. http://doi.org/10.1097/ PCC.0b013e318234a723 PMid:22067921

14. Christian MD, Joynt GM, Hick JL, Colvin J, Danis M, Sprung CL, et al. Chapter 7. Critical care triage. Recommendations and standard operating procedures for intensive care unit and hospital preparations for an influenza epidemic or mass disaster. Intensive Care Med. 2010;36(Suppl 1):S55-64. http:// doi.org/10.1007/s00134-010-1765-0

PMid:20213422

15. Morgan RW, Kienzle M, Sen Al, Kilbaugh TJ, Dewan M, Raymond TT, et al. Pediatric resuscitation practices during the coronavirus disease 2019 pandemic. Pediatr Crit 
care Med. 2020;21(9):e651-60. http://doi.org/10.1097/ PCC. 0000000000002512

PMid:32618677

16. Setia MS. Methodology series module 3: Cross-sectional studies. Indian J Dermatol. 2016;61(3):261-4. http://doi. org/10.4103/0019-5154.182410

PMid:27293245

17. Tabatabaei SA, Abbasi S. Risk assessment in social security hospitals of Isfahan Province in case of disasters based on the hospital safety index. Int J Health Syst Disaster Manag 2016;4(3):82. http://doi.org/10.4103/2347-9019.191108

18. Naser WN, Ingrassia PL, Aladhrae S, Abdulraheem W. A. A study of hospital disaster preparedness in South Yemen. Prehosp Disaster Med 2018;33(2):133-8. http://doi.org/10.1017/ S1049023X18000158 PMid:29455694

19. World Health Organization. Workload Indicators of Staffing Need. Geneva: World Health Organization; 2010. https:// www.who.int/workforcealliance/knowledge/toolkit/17/en. [Last accessed on 2021 Jul 10].

20. World Health Organization. Coronavirus Disease (COVID2019) Situation Reports. Geneva: World Health Organization; 2020. https://www.who.int/emergencies/diseases/novelcoronavirus-2019/situation-reports. [Last accessed on $2021 \mathrm{Jul}$ 10].

21. Singer AJ, Morley EJ, Meyers K, Fernandes R, Rowe AL, Viccellio $\mathrm{P}$, et al. Cohort of four thousand four hundred four persons under investigation for COVID-19 in a New York hospital and predictors of ICU care and ventilation. Ann Emerg Med. 2020;76(4):394-404. http://doi.org/10.1016/j. annemergmed.2020.05.011 PMid:32563601

22. Anjarsari ER. Disaster Preparedness Planning at Balung Regional Hospital, Jember Regency (Disaster Preparedness Plan at Balung Hospital, Jember Regency); 2016.

23. Liew MF, Siow WT, MacLaren G, See KC. Preparing for COVID-19: Early experience from an intensive care unit in Singapore. Crit Care. 2020;24(1):83. http://doi.org/10.1186/ s13054-020-2814-x

PMid:32151274

24. Samsuddin NM, Takim R, Nawawi AH, Alwee SN. Disaster preparedness attributes and hospital's resilience in Malaysia. Proc Eng. 2018;212:371-8. https://doi.org/10.1016/j. proeng.2018.01.048

25. Xie J, Tong Z, Guan X, Du B, Qiu H, Slutsky AS. Critical care crisis and some recommendations during the COVID-19 epidemic in China. Intensive Care Med. 2020;46(5):837-40. https://doi.org/10.1007/s00134-020-05979-7

PMid:32123994

26. Davies NG, Klepac P, Liu Y, Prem K, Jit M, CMMID COVID-19 Working Group and Eggo RM. Age-dependent effects in the transmission and control of COVID-19 epidemics. Nat Med. 2020;26:1205-11.

27. Parker J, White SM. Preparedness of intensive care units in South-East UK for influenza pandemic. $\mathrm{Br} \mathrm{J}$ Anaesth. 2006;96(6):805-6. https://doi.org/10.1093/bja/ael090 PMid:16698873

28. Nap RE, Andriessen MP, Meessen NE, dos Reis Miranda D, van der Werf TS. Pandemic influenza and excess intensive-care workload. Emerg Infect Dis. 2008;14(10):1518-25. https://doi. org/10.3201/eid1410.080440 PMid:18826813

29. Gabriel LE, Webb SA. Preparing ICUs for pandemics. Curr Opin Crit Care. 2013;19(5):467-73. https://doi.org/10.1097/ MCC.0b013e328364d645

PMid:23995125

30. Elhadi M, Msherghi A, Alkeelani M, Zorgani A, Zaid A, Alsuyihili A et al. Assessment of healthcare workers' levels of preparedness and awareness regarding COVID-19 infection in low-resource settings. Am J Trop Med Hyg. 2020;103(2):828-33. https://doi. org/10.4269/ajtmh.20-0330 PMid:32563273

31. Huh S. How to train the health personnel for protecting themselves from novel coronavirus (COVID-19) infection during their patient or suspected case care. J Educ Eval Health Prof. 2020;17:10. https://doi.org/10.3352/jeehp.2020.17.10 PMid:32150796

32. Shi Y, Wang J, Yang Y, Wang Z, Wang G, Hashimoto K, et al. Knowledge and attitudes of medical staff in Chinese psychiatric hospitals regarding COVID-19. Brain Behav Immun Health. 2020;4:100064. https://doi.org/10.1016/j.bbih.2020.100064 PMid:32289123 